Chapter 18

\title{
Differentiating Applications of Hydraulic Fracturing
}

\author{
Joel Adams and Clem Rowe \\ Additional information is available at the end of the chapter \\ http://dx.doi.org/10.5772/56114
}

\begin{abstract}
Hydraulic fracturing has received abundant media attention in recent years due to a rapid increase in the use of the technique in combination with horizontal drilling technology to produce oil and gas resources from tight reservoirs. Hydraulic fracturing techniques are also used in a variety of other applications that are unrelated to oil and gas production, including tunnel and dam construction, enhanced geothermal energy, carbon sequestration, groundwater remediation, block cave mining, rock burst mitigation, and water well development.
\end{abstract}

Environmental concerns associated with large-scale hydraulic fracturing in oil and gas reservoirs have resulted in political efforts to ban the technique with legislation now in place in certain states in the US and countries around the world. Concerns include soil and groundwater contamination and induced seismicity. A clear understanding of how hydraulic fracturing techniques are used in various applications is important to avoid unintended consequences of any regulations aimed at hydraulic fracturing in the oil and gas industry. The methodology for each application varies widely in terms of scale, pressures applied, additives, and fracture propagation. Mining rock stress measurements, for instance, focus primarily on the breaking strength of rock, and can be conducted with a small-volume highpressure pump that produces only a few liters/minute. The total volume of water injected may be on the order of tens or hundreds of liters. A typical oil and gas well hydraulic fracture treatment, on the other hand, requires millions of litres of injected proprietary fluid and proppant in order to propagate and maintain the fracture effectively into the reservoir. Though both applications are termed "hydraulic fracturing", they differ greatly in terms of potential impacts to the environment.

This paper characterizes a range of hydraulic fracturing applications in terms of the objectives, techniques, and potential for environmental concerns associated with the standard 
methods. A nomenclature that clearly differentiates discrete applications is presented that is intended to help prevent the lumping of all hydraulic fracturing techniques into a single basket.

Keywords: hydraulic fracturing, rock stress measurements, applications

\section{Introduction}

The process of hydraulic fracturing as applied to drilled holes has been much in the news of late with a number of vociferous and often emotional debates about its potential to harm the environment particularly with reference to groundwater sources and also the potential to generate seismic events. However, all of this debate has been focused on a process typically referred to just as "fracking".

A recent $\mathrm{BBC}$ article [1] gives us the following relationship between the controversial process of "fracking" and the more generic term "hydraulic fracturing":

\section{"What is fracking?}

The process of drilling down and creating tiny explosions to shatter and crack hard shale rocks to release the gas inside. Water, sand and chemicals are injected into the rock at high pressure which allows the gas to flow out to the head of the well. The process is carried out vertically or, more commonly, by drilling horizontally to the rock layer. The process can create new pathways to release gas or can be used to extend existing channels.

\section{Why is it called fracking?}

It is shorthand for hydraulic fracturing and refers to how the rock is fractured apart by the high pressure mixture".

A further BBC article [2] headlined "Bulgaria bans shale gas drilling with 'fracking' method", further informs us that:

"Hydraulic fracking involves releasing gas trapped in rocks by pumping in water mixed with sand and chemicals at high pressure."

Sadly, these definitions, although technically correct, in their limited ways, do not pay any attention to the fact that the case described is only one of many applications of hydraulic fracturing that is applied in drill holes.

It is important to note that this paper is not intended to differentiate "good" fracking from "bad" fracking. The authors recognize that while certain types of hydraulic fracturing do carry a greater environmental risk, all hydraulic fracturing can be conducted in an environmentally responsible manner. However, a more complete definition of hydraulic fracturing is required which also specifies the application for which the process is applied. For example, apart from shale gas production, other applications for hydraulic fracturing include:

- Water well production enhancement 
- Block Cave Mining (Hydraulic Pre-conditioning)

- Rock Stress Determination for Geotechnical Design (Tunnels, Dams, Foundations)

- Conventional oil and gas production

- Geothermal (hot dry rock, or "enhanced' geothermal)

- Carbon Sequestration (Carbon Capture and Storage)

- Coalbed Methane Development

- Coal Mine Methane Drainage

- Rock burst mitigation

All of the above use a process they term "hydraulic fracturing". The most general definition of which would be:

Hydraulic fracturing is a process whereby a fluid (often water with or without additives) at high pressure is applied to a borehole to create a fracture (or fractures) in the surrounding rock mass.

Before entering further discussion concerning definitions and terminology it is instructive to take a more detailed look at each of the various applications listed above.

\section{Hydraulic fracturing applications}

\subsection{Water well production enhancement}

As studied and described by W. H. Williamson, D. R. Woolley [3] in the 1970s, hydraulic fracturing has long been used as a method to improve the yield of water wells in fractured rock aquifers. It is widely used for domestic wells in many regions of the USA (for example, New England, Texas, Washington) and in some other locations such as Andhra Pradesh, India.

In water well hydraulic fracturing, often referred to as hydrofracking, a section of the well is isolated using packers and water is introduced to generate pressures up to approximately 3000 psi (207 bar) to wash out existing fractures and propagate them to connect with others within the aquifer. Since the pressure is quite limited it is doubtful if this process generates any new fractures though may do in some circumstances. The volume of water introduced per fracture is typically less than 1000 litres. This process generally does not use any proppant or additives in the injected water.

\subsection{Block cave mining (Hydraulic pre-conditioning)}

Block caving is an underground mass mining method where the extraction of the ore depends largely on the action of gravity. A shaft and horizontal galleries are driven to below the ore 
body and a relatively thin horizontal layer of the overhead supporting rock is removed, using standard mining methods. Removal of this support allows the ore to cave into the galleries by gravity from where it is removed to allow caving to continue. [4]

In the event of a massive, un-fractured ore body, some form of pre-conditioning is needed to initiate caving and to reduce the size of caving materials. Intensive hydraulic fracturing in boreholes drilled into the ore body is one of the favoured methods of performing this preconditioning process.[5] Fracturing pressures can be up to 10,000 psi and pumped volumes of pure water are typically of the order of $4-5,000$ litres per fracture though can be much larger depending on pump size and pressure response. [6]

\subsection{Rock stress determination for geotechnical design (Mines, tunnels, dams, foundations)}

In hydraulic fracturing for stress determination [7] also referred to as hydrofracturing, and sometimes as minifracing, a section of borehole is isolated between two inflatable packers and the pressure is raised by pumping fluid into it at a controlled rate until a fracture occurs in the borehole wall. Pumping is stopped and the pressure in the interval is allowed to stabilize. The pressure is then reduced to the pore pressure level of the rock formation, and the pressurization/depressurization process is repeated several times maintaining the same flow rate. The magnitudes of the principal stresses are calculated from the various pressure readings.

Normally only pure water is used and pressures are typically a maximum of 6,000 psi but can be as high at 15,000 psi. Flow rates are low at about 1 litre per minute with the total volume pumped per fracture typically being less than 100 litres.

Stress testing may also be carried out in oil and gas wells in which case the rates and volumes are much larger though this is primarily because the equipment normally available dictates minimum flow rates of 40 to 160 litres per minute.

\subsection{Conventional oil and gas production}

Hydraulic fracturing has long been used in the oil and gas industry for the stimulation of traditional reservoirs. To quote [8]:

\footnotetext{
"Since Stanolind Oil introduced hydraulic fracturing in 1949, close to 2.5 million fracture treatments have been performed worldwide. Some believe that approximately $60 \%$ of all wells drilled today are fractured."
}

Clearly then hydraulic fracturing is a major tool used by the oil and gas industry worldwide and not just in the newer unconventional or tight gas fields.

Fracture stimulation in this industry typically uses injected fluid that includes additives, many of which are proprietary, and proppant. The latter is typically graded sand (20/40 grade being mostly favoured) but the type, size, and amount selected are based on closure stress and 
conductivity of thefractureneeded forthedesired stimulationeffect. Thefunction of theproppant when injected into fractures is to keep them open after the fracturing pressure dissipates. Most of the injectate additives are designed to increase the proppant carrying capacity of the fluid.

Because the formation being treated generally is already permeable, very high injection flow rates are necessary in order to build pressure in the treatment region. To quote from [9]:

\footnotetext{
"As the resistance to flow in the formation increases, the pressure in the wellbore increases to a value that exceeds the breakdown pressure of the formation that is open to the wellbore. Once the formation "breaks-down", a crack or fracture is formed, and the injected fluid begins moving down the fracture."
}

Injection pressures typically range up to around 6,000 psi but can be as high as 20,000 psi. The total volume of injected fluid is generally very high at greater than $1 \mathrm{ML}\left(10^{6}\right.$ Litres).

\subsection{Geothermal (Hot dry rock, or "enhanced" geothermal)}

Enhanced geothermal energy production (EGS) involves the injection of water in a well, heating the water in the subsurface, and extraction of the same water as steam or hot water from a second well. Hydraulic fracturing is utilized to establish a flow pathway between the injection and extraction wells. The magnitude of fracturing operations for EGS is dependent on the well spacings required to achieve effective heat transfer for each particular project.

EGS wells have typically been stimulated by injection at pressures below or just up to the minimum principal stress magnitude. This increases the pressure in the reservoir and promotes shear slip on existing natural fractures. Hydraulic fracturing associated with enhanced geothermal energy production has been undertaken at least since the work reported in [10] and its precursors. This early work being more "proof of concept" generally seems to have involved quite small hydraulic fracture treatments. More recent developments such as that in planning adjacent to the Newbury volcano in Oregon [11] envisage much more large scale stimulation to open up large subterranean contact areas to injected water for the large scale production of steam. Although scant information on the scale of these projects is available, it is assumed that they will involve hydraulic fracture treatments similar to those employed in conventional oil and gas reservoirs.

\subsection{Carbon sequestration (Carbon capture and storage)}

Quoting from [12]:

\footnotetext{
"Geologic carbon sequestration is becoming an increasingly viable method for reducing the rate of greenhouse gas emissions through the injection of $\mathrm{CO} 2$ into geologic reservoirs."
} 
The range of suitable "geologic reservoirs" includes coal basins, depleted oil and gas reservoirs and saline aquifers. Although this technology is still under development with many studies being conducted worldwide there is, as yet, no large scale development. It is anticipated, depending on the storage target and it is noted that the targets mentioned above are high permeability reservoirs, that hydraulic fracturing may play a role in this industry. Again, we have assumed that hydraulic fracturing in this role will be similar in scale to that employed in conventional oil and gas.

\subsection{Coalbed Methane (CBM) development}

Hydraulic fracturing in CBM wells is performed in similar fashion and for similar purposes as for conventional oil and gas wells [9]. The major difference is that of scale in that the CBM reservoirs, normally being nearer to surface, require lower pressures, less volume and fewer (if any) additives in the fracturing fluid.

Fracture pressures are up to 5,000 psi and total injected volume per fracture ranging up to 500,000 litres.

\subsection{Coal Mine Methane (CMM) drainage}

The objective of CMM drainage is to reduce the methane content of coal seams prior to mining both for safety and environmental reasons and also as an additional revenue stream. Hydraulic fracturing both with and without sand proppant is used to enhance the production of methane from the coal. These treatments are conducted from both vertical holes and horizontal, in-seam drill holes. The scale of treatments varies widely but are typically smaller than CBM stimulation fractures, especially if carried out from underground.

\subsection{Rock burst mitigation}

This is a relatively new area of application for hydraulic fracturing and remains in the early evaluation stage with no large scale deployment as yet. As noted in [13], hydraulic fracturing is being investigated as a means of reducing in-situ rock stress to ameliorate the frequency and severity of rock burst incidents.

Typically such work is being performed in small diameter boreholes at high pressure but low flow rates, similar to those encountered in stress testing although more effort is made towards propagation of the fractures.

\section{Characterization}

What do all of these applications have in common, and how do they differ? To differentiate, we'll look at some of the physical aspects of fracturing:

Injectate Volume - How much fluid is injected? Note that we could also consider injection flow rate here although the total volume injected is clearly related to flow rate. 
Nature of the Injectate: Is it just water or does it include chemical additives?

Proppant: Is proppant being injected to hold the fracture open after treatment?

Fracture Propagation: Are we creating a fracture simply to determine the strength of the rock and stopping, or after initiation, are we going to try to propagate that fracture further?

Pressure: What pressures are applied?

Fracture/NoFracture: Are we actually creating new fractures, or simply opening existing fractures? Are there certain applications that really aren't fracturing at all?

A consideration of each of the above activities in relation to the suggested characterization criteria is given in Table 1.

\section{Terminology to differentiate hydraulic fracturing}

From Table 1 it may be seen that pressures tend to be relative to the treatment depth as would be expected. Those treatments based on conventional oil and gas methods are necessarily similar - all using additives of some sort and usually proppant to keep fractures open. In fact, the composition of the injected fluid may be viewed as one of the major differentiating characteristics between different types of treatments.

\begin{tabular}{lllllll}
\hline Application & $\begin{array}{l}\text { Injectate } \\
\text { Volume (L) }\end{array}$ & Additives & Proppant & Pressure & Propagation & True \\
\hline O\&G Tight Reservoirs & $10^{6}$ & Yes & Yes & Up to 15K psi & Yes & Yes \\
\hline Water Wells & $<10^{3}$ & No & Some & $<3,000$ psi & Yes & Few \\
\hline Block Cave Mining & $10^{4}$ & No & Some & $<10 \mathrm{~K}$ psi & $<100 \mathrm{~m}$ & Yes \\
\hline Rock Stress Testing & $<10^{3}$ & No & No & $<15 \mathrm{~K} \mathrm{psi}$ & Limited & Yes \\
\hline Conventional Oil \& Gas & $10^{6}$ & Yes & Yes & Up to 15K psi & Yes & Yes \\
\hline Enhanced Geothermal & $10^{7}$ & Yes & Yes & Up to 15K psi & Yes & Yes \\
\hline Carbon sequestration & $10^{6}$ & Yes & Yes & Up to 10K psi & Yes & Yes \\
\hline CBM & $<5 \times 10^{5}$ & Some & Yes & $<5 \mathrm{Kpsi}$ & Yes & Yes \\
\hline CMM & $10^{4}$ & Some & Some & $<5 \mathrm{Kpsi}$ & Yes & Yes \\
\hline Rock Burst Mitigation & $<10^{3}$ & No & No & $<15 \mathrm{~K} \mathrm{psi}$ & Limited & Yes \\
\hline
\end{tabular}

Table 1.

Another major differentiating characteristic is the volume of injected fluid. Smaller hydraulic fracturing treatments, such as those for stress testing use small volumes of fluid where as larger treatments, such as conventional oil and gas use large volumes of fluid. Therefore, it is 
proposed that these characteristic are those which should be chosen as the defining characteristic for a terminology to differentiate between different "types" of hydraulic fracturing with injected volume taking the primary role.

An obvious approach would be to use the terms, mini-frac, midi-frac, macro-frac, etc, however the term mini-frac is already in use for both stress testing and for conventional and unconventional oil and gas. Alternatively, to use, for example, Class 1, 2, 3, etc, is in danger of being confused with the USEPA well classification system.

It is suggested that a practical approach may be to rely on a "Typing" system such as that described below.

Type A - no actual new fractures created though exisiting fractures are opened and possibly washed out. This Type would apply to water well hydraulic fracturing and such geotechnical tests as hydro-jacking. As this is an "outlier" with no real fracture occurring it is felt unnecessary to specify the injected volume though it would be typically less than 10,000 litres.

Type B - new fractures are generated but little or no attempt is made to propagate these fractures. Examples would include stress testing and rock burst amelioration. Injected fluid volume is to be limited to less than a few hundred litres per fracture.

Type $\mathbf{C}$ - new fractures are generated and some attempt is made to propagate these fractures. Typically injected fluid volumes per fracture are to be limited to less than, say 100,000 litres per fracture. Hydraulic fracturing for block caving, CMM and possibly CBM would fall into this category. Given that these may also include proppant and or additives in the injected fluids some additional nomenclature is appropriate to account for these additions. In an attempt to keep it simple, this could be:

Type C - plain water

Type $\mathrm{C}-\mathrm{a}$ - water with additives

Type C-p - water with proppant

Type C-ap - water with additives and proppant

Type $\mathbf{D}$ - new fractures are generated and these are propagated to the size required to produce the stimulation desired. Typically injected fluid volumes per fracture are more than, say 100,000 litres per fracture. Most CBM, conventional and multi-zonal, unconventional hydraulic fracturing would fit into this category. This Type would also use the suffix notation given above for Type $\mathrm{C}$ to further specify the injected fluids.

\section{Conclusions}

Hydraulic fracturing is a process used in many industries for different applications and purposes. It may be characterized and differentiated across this range of industries in terms of injected volume and the composition of the injected fluids. 
A new terminology has been proposed to allow clear differentiation between the many different types of hydraulic fracturing operations. The purpose of this terminology is to enable practitioners, regulators and the general public a clear means of making the distinction between these many different operations.

\section{Acknowledgements}

The authors wish to acknowledge and express appreciation for the contribution of our reviewer, Rob Jefferies, to the correctness and completeness of this paper.

\section{Author details}

Joel Adams ${ }^{1^{*}}$ and Clem Rowe $2^{2^{*}}$

*Address all correspondence to: joel@inflatable-packers.com; clem@inflatable-packers.com

1 Inflatable Packers International LLC, Australia

2 Inflatable Packers International Pty Ltd, Australia

\section{References}

[1] BBC News UK online on 2/11/2011

[2] BBC News Europe online on 19/01/2012

[3] Williamson, W. H, \& Woolley, D. R. Hydraulic fracturing to improve the yield of bores in fractured rock, Australian Government Publishing Service, (1980).

[4] TechnomineMining Technology. Block Caving http://technology.infomine.com/ reviews/Blockcaving/welcome.asp?view=fullaccessed 5/01/(2013).

[5] Van As, A, \& Jeffrey, R. G. Hydraulic Fracturing as a Cave Inducement Technique at Northparkes Mine, MassMin 2000 Proceedings, (2000). , 165-172.

[6] Private communication

[7] Astm, D. Standard Test Method for Determination of the In-Situ Stress in Rock Using the Hydraulic Fracturing Method

[8] MontgomeryCarl T. and Smith, Michael B. Journal of Petroleum Technology, Dec. (2010). Hydraulic Fracturing- History of an Enduring Technology., 26-32. 
[9] USEPA R-04-003 Appendix A Hydraulic Fracturing White PaperJune (2004).

[10] Rummel, F, \& Kappelmayer, O. The Falkenberg Geothermal Frac Project: Concepts and Experimental Results, In: Nemat-Nasser S, Abé H., Hirakawa S (ed) Hydraulic Fracturing and Geothermal Energy, (1983). , 59-74.

[11] Wired Science: Energy Company Plans to Frack a Volcanoreported 10.04.(2012). http://www.wired.com/wiredscience/2012/10/newberry-volcano-fracking/accessed 6/01/2013)

[12] Johnson, S. M, \& Morris, J. P. Hydraulic Fracturing Mechanisms In Carbon Sequestration Applications, 43rd U.S. Rock Mechanics Symposium \& 4th U.S.- Canada Rock Mechanics Symposium, June July 1, (2009). Asheville, North Carolina, 28.

[13] Yan Jun FengXiu Wei Shi, Hydraulic Fracturing Process: Roles of In Situ Stress and Rock Strength, (2012). Advanced Materials Research, 616-618, 435 